\title{
Physical Activities to Youth Outside School
}

\author{
Kujtim Kapedani*, Florian Mema \\ Department of Sport, Faculty of Movement Sciences, Sports University Tirana, Albania
}

DOI: $10.36348 /$ jaspe.2020.v03i08.002

| Received: 26.07.2020 | Accepted: 02.08.2020 | Published: 09.08.2020

*Corresponding author: Kujtim Kapedani

Abstract

Physical activities in young people. The concept of the game as a cultural phenomenon was partly influenced by the ideas of different studios. The aim of this study was to examine the nature of the physical activities practiced by young people in their leisure time through questionnaires. Study sample. This study involved 126 young people: 66 girls and 60 boys, aged between 15 and 18 years old. They study in three different schools of Tirana. In both studies there are three main reasons for practicing informal physical activities: "because they like it", "for fun and enjoyment" and "for exercising". Since the type of activities carried out during leisure time will affect many aspects of life persons, it is important to prevent these young people from becoming adults and spending most of their leisure time in sedentary activities.

Keywords: Physical activities, different game, leisure time, girls, boys.

Copyright @ 2020: This is an open-access article distributed under the terms of the Creative Commons Attribution license which permits unrestricted use, distribution, and reproduction in any medium for non-commercial use (NonCommercial, or CC-BY-NC) provided the original author and source are credited.

\section{INTRODUCTION}

Food and health problems in young people are related to certain attitudes and behaviors of the lifestyle and more specifically to physical activity at school age. How physically active the school youth are, how many hours a day they perform physical movements and activities, are these activities organized or individual and the like, are questions that create a certain picture from which often genuine problems arise health, which are often more immediate [1].

Over the years, the significance of the word "sport" has adapted to the social changes that have happened. The concept of the game as a cultural phenomenon was partly influenced by the ideas of different authors in the field of sports and movement.

The importance of this research is that we will gather information about the nature of the physical activities practiced by young people in their leisure time [2].

Continuous physical activity, even if moderate, creates significant health benefits, including good mood, self-esteem, better physical appearance, reduction of obesity, hypertension, cardiovascular disease, diabetes and osteoporosis [3].
So assessments of physical activity are very positive and beneficially affect the health of young people whenever they develop periodically or daily [4].

In school, a considerable place is devoted to the exercise of physical activities not only in the curriculum in the physical education class, but also in the development of other activities of a fun, entertaining and health nature [5].

All these influence the creation of certain movement stereotypes in young people during the school week. But, despite this, there is always a need for improvement as the situation according to the figures is not always the best possible [6].

The aim of this study is to obtain information about the habits that young people have in Tirana during the practice at leisure time physical activity. Informal physical activity is referred to as any physical practice that meets these three conditions:

1. Performed outside the educational system.

2. Not headed by a professional.

3. Performed collectively or individually.

\section{METHODOLOGY}

Procedure we talked to the principles of different schools. We gave them the questionnaires and explained to them the protocol to complete them. This study involved 126 young people: 66 girls and 60 boys, 
aged between 15 and 18 years old. They study in three different schools of Tirana. Documentary evidence, to develop this research a questionnaire that included modified items of [4]:

- What kind of physical activity in leisure time do you practice?

- In general, how often do you practice these activities?
- What is the main reason for practicing these physical activities in leisure time?

- What is the main reason for not practicing any physical activity?

\section{RESULTS}

The following results obtained from questionnaire replies are presented in my six variables below:

Table-1: First variable

\begin{tabular}{|l|l|}
\hline \multicolumn{1}{|c|}{ Boys (\%) } & \multicolumn{1}{c|}{ Girls (\%) } \\
\hline 1. Playing with their friends, not in a team $(21.26 \%)$. & 1. Walking (13.17\%). \\
2. Cycling $(13.74 \%)$. & 2. Playing football $(8.77 \%)$. \\
3. Volleyball $(15.50 \%)$. & 3. Cycling $(9.11 \%)$. \\
4. Walking $(12.09 \%)$. & 4. Going to the mountains $(7.52 \%)$. \\
5. Playing football $(11.64 \%)$. & 5. Playing basketball not in a team $(6.56 \%)$. \\
\hline
\end{tabular}

Table-2: Second variable

\begin{tabular}{|c|c|}
\hline Boys (\%) & Girls (\%) \\
\hline 1. Walking (66\%). & 1. Walking (62.92\%). \\
\hline 2. Cycling (18\%). & 2. Dancing $(18.33 \%)$. \\
\hline 3. Playing soccer with theirs friends, not in a team $(14 \%)$. & 3. Playing volley with theirs friends, not in a team $(12.81 \%)$. \\
\hline 4. Playing basketball with friends, not in a team $(11.52 \%)$. & 4. Playing different games with a ball, not in a team $(9.14 \%)$. \\
\hline 5. Playing to different games with a ball ( $8{ }^{\circ}$ & $\begin{array}{l}\text { 5. Doing other physical activities with friends, not in a team } \\
(8.61 \%) \text {. }\end{array}$ \\
\hline
\end{tabular}

Table-3: Third variable

\begin{tabular}{|l|l|}
\hline \multicolumn{1}{|c|}{ Boys (\%) } & \multicolumn{1}{c|}{ Girls (\%) } \\
\hline $\begin{array}{l}\text { 1. Cycling (27\%). } \\
\text { 2. Playing soccer with their friends, not in a team }(26 \%) .\end{array}$ & $\begin{array}{l}\text { 1. Cycling (14.51\%). } \\
\text { 3. Playing different games with a ball }(11 \%) .\end{array}$ \\
$\begin{array}{l}\text { 4. Playing basketball with their friends, not in a team }(9 \%) . \\
\text { 5. Doing other physical activities with friends, not in a team (7.88\%). }\end{array}$ & $\begin{array}{l}\text { 3. Dancing }(7.15 \%) . \\
\text { 4. Going to the mountains }(6.8 \%) .\end{array}$ \\
\hline
\end{tabular}

Table-4: Fourth variable

\begin{tabular}{|l|l|}
\hline \multicolumn{1}{|c|}{ Boys (\%) } & \multicolumn{1}{c|}{ Girls (\%) } \\
\hline 1. Playing soccer with their friends, not in a team (25\%). & 1. Cycling (12.36\%). \\
2. Playing basketball $(19 \%)$. & 2. Dancing (16.25\%). \\
3. Going to the mountains (14\%). & 3. Volleyball $(13.33 \%)$. \\
4. Cycling (19.22\%). & 4. Playing soccer with their friends, not in a team $(12.1 \%)$. \\
5. Playing table tennis (9\%). & 5. Playing basketball with friends, not in a team $(9.54 \%)$. \\
\hline
\end{tabular}

Table-5: Fifth variable

\begin{tabular}{|l|l|}
\hline \multicolumn{1}{|c|}{ Boys (\%) } & \multicolumn{1}{c|}{ Girls (\%) } \\
\hline 1. Swimming (11\%). & 1. Cycling (11\%). \\
2. Going to the mountains $(27 \%)$. & 2. Going to the mountains $(26.55 \%)$. \\
3. Playing tennis, not in a team $(15 \%)$. & 3. Dancing $(38.71 \%)$. \\
4. Playing table tennis, with friends, not in a team (9\%). & 4. Volleyball $(16.77 \%)$. \\
5. Cycling $(23 \%)$. & 5. Playing soccer with their friends, not in a team $(20.13 \%)$. \\
\hline
\end{tabular}

Table-6: Sixth variable

1. Skipping (18\%).

2. Playing with the elastic bands $(12 \%)$.

3. Jumping with rope (9\%).

4. Balance $(6 \%)$.

5. Playing different games in the park $(7 \%)$.

Girls (\%)

1. Playing with the elastic bands (13.4\%).

2. Playing different games in the park $(12.6 \%)$.

3. Balance $(11.52 \%)$.

4. Climbing (8.04\%).

5. Jumping with rope $(7.29 \%)$. 
Tables 7 and 8 are outlined reasons for the practicing leisure time physical activities.

Table-7: Comparative of the reasons that boys and girls have for practicing physical activities in leisure time.

\begin{tabular}{|l|c|c|}
\hline Physical activities in leisure time & Boys (\%) & Girls (\%) \\
\hline A- "for fun and enjoyment" & 16 & 31,5 \\
\hline B- "to meet friends" & 10 & 18,9 \\
\hline C- "for the fun of exercising" & 13 & 6,25 \\
\hline D- "because they like it" & 49 & 36,6 \\
\hline E- "stay slim" & 0 & 4,45 \\
\hline F- "to disconnect" & 0 & 0 \\
\hline G- "to stay and keep healthy" & 4 & 0 \\
\hline H- "to become an athlete" & 8 & 2,3 \\
\hline
\end{tabular}

Table-8: Comparative of the reasons that boys and girls have for not practising physical activities in

leisure time

\begin{tabular}{|l|c|c|}
\hline \multicolumn{3}{|c|}{ Reasons for not practicing \% } \\
\hline & Boys & Girls \\
\hline Did not respond & 97 & 95,7 \\
\hline Lazines & 3 & 4,3 \\
\hline
\end{tabular}

\section{DISCUSSION AND CONCLUSIONS}

From the above data we note that in general there is a tendency to reduce the number of physically active Albanian youth, which is a growing problem for their health.

It is worth noting that the practiced physical activities by both boys and girls which is done every day or twice or three times a week does not require any other person. Regarding the differences between genders, the greatest occurs in the activities which were practiced on holidays. Games with the ball are the only common activity between boys and girls. With regard to the reasons for practicing activities, the data of this study is in line with the survey on the sport habits of Albanian. In both studies there are three main reasons for practicing physical activities: "because they like it", "for fun and enjoyment" and "for exercising"[7].

In the years 2018-19 walking appears for the first time as one of the most practiced physical activities. We understand that this data requires a deeper reflection. Since the type of activities carried out during leisure time will affect many aspects of life pupils, it is important to prevent these young people from becoming adults and spending most of their leisure time in sedentary activities.

One factor that affects the development of mobility activity among young people is the lack of sports fields in residential centers. In these centers, sports fields are "occupied" by high-rise buildings and no longer exist, depriving them of the opportunity to perform activity motor and physical.

Society is changing and with it also people's habits. Therefore, some changes in leisure time are expected. The five most practiced activities by Albanians from 2000 to the year 2019 were:

1. Being with the family.

2. Watching television.

3. Being with friends.

4. Reading books and newspapers.

5. Listening to music.

Another "bitter" reality is that, in the new residential centers that have been set up in all major cities, only housing has been considered, but not social facilities, including sports fields. In these conditions, young people move considerable distances from their homes to the concentrated sports fields, but even in these fields, in certain cases they have to pay to use them.

\section{Conflict of interest}

Authors declare that they have no conflict of interest

\section{ACKNOWLEDGMENTS}

We wish to thank all: young people and parents, who helped and participated in our study.

\section{REFERENCES}

1. M.S.I. (1989). "Educazione Sanitaria e Promozione della Salute” 12(2); 107

2. Gaxho, I. (2002). "Physical education out school". Curriculum and schools. I.S.P. Tirana nr, 2; 103 116.

3. Susan, G. Millstein., \& Anne, C. Petersen. (1993). "Promoting the Health of Adolescents". Oxford University; 181

4. Pesa, J. (1999). "Psychosocial factors associated with dieting behaviors among female adolescents", Journal of School Health; 196-201

5. Subashi, G., \& Daci, J. (2004). "Didaktika $e$ edukimit fizik". Tiranë; 58-62

6. M.SH.R.SH. (2003). "Strategjia e shëndetit të fëmijve". Tiranë; 63

7. Dashi, T., \& Dashi, E. (2007). "Physical education in schools ". Tirana. 155-156

8. Kuqo, S.H. (2005). The basics of gymnastics terminology, Tirana.

9. www.creative-comm.com 